\title{
ESTUDOS CULTURAIS E ESTUDOS DE GÊNERO: PROPOSIÇÕES E ENTRELACES ÀS PESQUISAS EDUCACIONAIS
}

\author{
D. Q. Beck' e B. S. Guizzo' \\ ${ }^{1}$ Instituto de Educação, Universidade Federal do Rio Grande (IE/FURG) \\ 'Programa de Pós-Graduação em Educação, Universidade Luterana do Brasil (PPGEdu/ULBRA) \\ dinahqbeck@gmail.com -bguizzo_1@hotmail.com
}

Artigo submetido em agosto/2013 e aceito em setembro/2013

\section{RESUMO}

Este artigo tem o interesse de proporcionar ao/a leitor/a uma análise acerca da relação estabelecida entre dois distintos campos de estudos, os Estudos de Gênero e os Estudos Culturais, os quais têm fundamentado as pesquisas desenvolvidas no âmbito das temáticas que têm mobilizado nossos estudos e investigações, sejam elas infância, cultura, consumo, gênero, sexualidade, embelezamento, produção e política dos corpos. Para tanto, nos ocuparemos, nessa argumentação, com alguns movimentos discursivos: após situar a importância atribuída a esses campos nas pesquisas educacionais vinculadas a perspectiva pós-estruturalista de análise, bem como o modo como operamos com eles, interessa-nos discutir e problematizar algumas de suas características, demarcando sua profícua relação. Finalizamos essa narrativa ressaltando suas contribuições em nossas investigações que discutem a produção de identidades de gênero e culturais à infância contemporânea.

PALAVRAS-CHAVE: Estudos Culturais, Estudos de Gênero, Pesquisas Educacionais.

\section{CULTURAL AND GENDER STUDIES: PROPOSITIONS AND INTERLINKS TO EDUCATIONAL RESEARCHES}

\begin{abstract}
This article aims to provide the reader an analysis on the relationship established between two different fields of studies, Gender Studies and Cultural Studies, which have been the basis of researches developed within the themes that have stimulated our studies and investigations, such as childhood, culture, consumption, gender, sexuality, beautification, production, and politics of bodies. To do so, we focus our discussion on the study of some discursive practices. After considering
\end{abstract}

the importance assigned to these fields in educational researches linked to perspectives in poststructuralist analysis, as well as the way we deal with them, the intention is to discuss and question some of their features, emphasizing their productive relationship. In conclusion, it is necessary to mention their contributions to our investigations, which discuss the production of gender and cultural identities in contemporary childhood.

KEYWORDS: Cultural Studies, Gender Studies, Educational Researches. 


\title{
ESTUDOS CULTURAIS E ESTUDOS DE GÊNERO: PROPOSIÇÕES E ENTRELACES ÀS PESQUISAS EDUCACIONAIS
}

\section{SITUANDO POSICIONAMENTOS}

\begin{abstract}
O convite é deixarmos para trás o lago sereno das certezas e mergulharmos naqueles autores e teorizações nos quais encontremos fontes consistentes, ferramentas produtivas para a formulação de nosso problema de pesquisa, exatamente na medida em que eles nos convidem ao exercício da arte de pensar de outra forma o que pensamos, buscando tencionar essas mesmas fontes conceituais, ousando cotejá-las com outras talvez menos seguranças para nós e, especialmente, ousando estabelecer relações entre esses referenciais e as primeiras incursões que fazemos em nossos materiais empíricos (FISCHER, 2002, p.58).
\end{abstract}

Temos tomado como base em nossas investigações as teorizações e as pesquisas que vêm sendo desenvolvidas no campo dos Estudos de Gênero e dos Estudos Culturais, em especial àquelas vinculadas à vertente pós-estruturalista de análise, a qual tem procurado questionar verdades que se pretendem únicas, universais, absolutas e totalizantes.

A crítica pós-estruturalista, ao afrouxar a rigidez estabelecida em diversos sentidos pelo outro campo, o estruturalismo, tem se apresentado muito produtiva para a educação, na medida em que seus estudos não têm o intuito de, no âmbito de suas produções, descobrir e desvelar verdades. Pode-se afirmar que nessas investigações é central o processo de significação, no entanto, abrem espaço para indeterminações e incertezas como modos alternativos de se pensar e de se problematizar o objeto de investigação, acolhendo o entendimento de que é possível produzir saberes ao apresentar respostas provisórias e temporárias aos estudos.

Tal vertente teórica e as perspectivas dos Estudos de Gênero e dos Estudos Culturais têm se mostrado bastante produtivas para o desenvolvimento de nossas investigações, principalmente pelo fato de trazerem incertezas, indagações, questionamentos, dúvidas e reflexões que nos possibilitam, ao longo de nossos estudos, olhar de modos diferenciados, desconfiados e menos ingênuos ao pesquisado, reorganizando rotas e traçados da pesquisa, sem carregar a necessidade da busca por uma resposta certeira, correta, definitiva que viesse para desvendar/solucionar algo.

Com as perspectivas teóricas adotadas podemos afirmar estar aprendendo, constantemente, a operar com o transitório e com o provisório, em especial no que diz respeito às diferentes crianças e suas infâncias, como também à produção das identidades de gênero femininas. No entanto, é preciso considerar que esse não tem sido um aspecto simples e de fácil aprendizado, em especial por estarmos inseridas num campo como o da educação. Sabemos que por muito tempo (e ainda hoje) essa área produziu/produz pesquisas e estudos que visavam/visam apontar caminhos seguros, traçando direções, delineando recomendações, prescrevendo soluções.

Nesse sentido, como vinha sendo dito, apoiamo-nos nos Estudos de Gênero e nos Estudos Culturais, vinculados à vertente pós-estruturalista, suspeitando das visões unidirecionais e conclusivas, que visam apontar erros e seus culpados e, por assim fazer, apresentar uma solução universal às problemáticas e mazelas educacionais. Buscamos, com as perspectivas teóricas adotadas, um caminho inverso e diferenciado às pesquisas realizadas.

Os referidos campos de estudo, nos últimos anos, devido à produtividade de suas pesquisas e investigações desenvolvidas, vêm ganhando cada vez maior atenção e destaque, justamente por se oporem ao hibridismo das pesquisas de caráter prescritivo e regulador no 
campo da educação. No intuito de possibilitar uma análise acerca da polissemia de significados e contribuições de tais estudos, passaremos, a seguir, a apresentar algumas de suas especificidades.

\section{Estudos Culturais: composições teóricas e conceituais}

No que tange aos Estudos Culturais, vale grifar, conforme apontam estudos e pesquisas, que a sua institucionalização deu-se no alto dos anos 60 do século $\mathrm{XX}$, mais especificamente no Centro de Estudos Contemporâneos, da Universidade de Birmingham, na Inglaterra. Entretanto, a noção de que já se realizavam estudos nessa vertente culturalista foram direcionados por pesquisadores tais como Jesús Martín-Barbero (2003) e Nestor García Canclini (2001), argumentando, ainda, que não se tem como definir a sua origem em termos geográficos e teóricos. Tais pesquisadores ainda assentaram que, na ótica desses estudos, essas preocupações com o início dos Estudos Culturais não sejam questões centrais.

No entanto, é importante considerar que tais estudos suscitaram significativas mudanças na teoria cultural e nos entendimentos direcionados ao conceito de cultura. Entretanto, naquele período e espaço geográfico, as investigações desenvolvidas direcionavam (e é importante compreender que ainda hoje direcionam) atenção especial para a relação que se estabelece entre cultura e sociedade.

Por algum tempo as pesquisas dos Estudos Culturais fundamentaram-se, sobretudo, no marxismo, em especial até meados dos anos 80 do século passado. Isso não significa dizer que as teorizações marxistas deixaram, no cenário atual, de configurar a proposição teórica de algumas investigações desses estudos. O que pretendemos salientar é que pesquisas abordando a relação estabelecida entre cultura e sociedade, numa perspectiva pós-estruturalista, passaram a ser predominantes dentro da vertente teórica dos Estudos Culturais, recebendo, inclusive, atenção de outros campos, como é o caso dos Estudos de Gênero.

Primordialmente, as pesquisas de tendência marxista dos Estudos Culturais centravam análise no estudo das subculturas, ou das culturas negadas, criticando fortemente as noções elitistas e hegemônicas que traziam à tona o binômio alta e baixa cultura, hierarquizando-os. Com o passar dos anos e o crescimento/desenvolvimento das pesquisas em várias localidades do mundo, essa distinção/classificação deixou de ser relevante e o termo cultura passou a adquirir outros significados.

Cultura passou a ser compreendida como campo conflituoso de lutas, contestação e significados sociais, formas variadas dos grupos por meio dos quais são produzidos e recompostos sentidos e sujeitos, através da manifestação de singularidades, peculiaridades e particularidades dos distintos grupos sociais. A cultura, nessa perspectiva, não é entendida como $a$ manifestação orgânica e natural de toda uma comunidade, nem como domínio cultural isolado de um grupo social, demarcando o que seria o bom gosto da sociedade e assim caracterizando a cultura reconhecida e elitizada. A cultura destaca, nessa narrativa, seu caráter fundamentalmente produtivo e criativo, vista como ação, como atividade, como experiência que produz identidades e diferenças. Embora concepções de ordem mais conservadoras e tradicionais tentem imprimir o significado de que a cultura é um produto final, concluído, definitivo, da ordem da razão histórica da sociedade, ou ainda um conjunto pronto e acabado de regras, convenções, marcas e regulações sociais, sua produtividade denuncia a polissemia de seus sentidos e significados inscritos em diferentes e múltiplos grupos sociais que, por fim, transgridem, inovam, abandonam, reinventam, produzem o que viemos nomeando por culturas e identidades culturais. 
Cultura envolve uma rede de representações e discursos, adquirindo diferentes significados inscrita no social. Ou seja: a moda, a música, o cinema, etc., são exemplos dessa rede de discursos e representações sociais que carregam marcas culturais, as quais adquirem diferentes significados, relacionados aos distintos grupos que os produzem e que pelos seus sujeitos pertencentes, são também produzidos. Ainda vale registrar que, desse entendimento traçado de cultura, afastam-se ideias tradicionais que compreendem os valores e os hábitos de uma sociedade como fixos, universais, naturais e imutáveis.

Segundo Marisa Costa (2003, p. 36),

'Cultura' transmuta-se de um conceito impregnado de distinção, hierarquia e elitismos segregacionistas para um outro eixo de significados em que se abre um amplo leque de sentidos cambiantes e versáteis. Cultura deixa, gradativamente, de ser domínio exclusivo da erudição, da tradição literária e artística, de padrões estéticos elitizados e passa a contemplar, também, o gosto das multidões. Em sua flexão plural - 'culturas' - é adjetivado, o conceito incorpora novas e diferentes possibilidades de sentido. [grifos da autora]

No âmbito dos Estudos Culturais presume-se que o saber é produtivo sendo elaborado em conexão com as relações sociais e culturais no qual se funde. Sendo assim, verificamos atualmente que no campo da educação as pesquisas desenvolvidas se apresentam bem polarizadas e diversificadas, não estando vinculadas necessária e exclusivamente aos aspectos referentes à educação escolar. O saber produzido, o qual fora anteriormente mencionado, não é um legado exclusivamente escolar. Muitas questões de pesquisa têm sido elaboradas buscando discutir as produções sociais e culturais de saber desenvolvidas em variadas instâncias, como a televisão, o cinema, as novelas, a publicidade, as revistas, etc.

Nessa mesma direção, ampliando a noção de cultura, nesses campos de investigação, até mesmo a noção cristalizada de tempo histórico recebe outra conotação. Imersa nessas perspectivas teóricas é compreendido que vivemos em um tempo multifacetado, marcado por mudanças e transformações, pelo seu caráter efêmero, passageiro e transitório.

Nesse tempo no qual vivemos, em que tudo muda velozmente, somos, a todo o instante, apresentados a uma série de novidades que se pretendem universais e totalizantes em especial em sociedades ocidentais como a nossa. Novidades essas, que na complexidade das relações sociais mostram-se cambiantes, voláteis, descartadas e deixadas num esquecimento prófugo assim que demais invencibilidades passam a existir, e tudo isso em uma mostra da necessidade de "pertencimento" que envolve as pessoas (BAUMAN, 2008). Esta é uma das inúmeras características que marcam o tempo presente, ou ainda, o contemporâneo.

\footnotetext{
Vivemos num mundo social onde novas identidades culturais e sociais emergem, se afirmam, apagando fronteiras, transgredindo proibições e tabus identitários, num tempo de deliciosos cruzamentos de fronteiras, de fascinante processo de hibridização de identidades. É um privilégio, uma dádiva, uma alegria, viver num tempo como esse, num tempo assim... (SILVA, 2001, p. 7).
}

Aprofundando nosso olhar sobre esse mesmo tempo e processo histórico observamos, em especial, desde a segunda metade do século passado, que produzimos, somos produzidos e assistimos ao advento e à evolução de inúmeras inovações e aparatos tecnológicos que, definitivamente, romperam com antigos modos de estabelecer e desenvolver comunicação. Por conta desta premissa, imprimiram-se novos ritmos, espaços, tempos, acontecimentos, estilos de vida e modos de ser às pessoas. Tais fatos carregam consigo um elemento simbólico fundamental 
em termos de análise: nestas sociedades configuram-se e operam-se modos distintos de se constituir, produzir e exercer educação, possibilitando que várias instituições sociais também tomem para si tal tarefa.

É nesse sentido, que outro conceito, o de "pedagogia cultural" (GIROUX, 1995), merece destaque. Ele traz consigo o entendimento de que ocorre pedagogia (educação) em todo o lugar em que o conhecimento é produzido e os saberes circundantes deste processo excedem e vão além dos limites impostos pelas instituições familiar e escolar. Ainda concebe a cultura como campo privilegiado do saber, na qual são produzidas práticas culturais de significação que educam.

Nas palavras de Henry Giroux e Peter McLaren (1998, p. 144):

Existe pedagogia em qualquer lugar em que o conhecimento é produzido, em qualquer lugar em que existe a possibilidade de traduzir a experiência e construir verdades, mesmo que essas verdades pareçam irremediavelmente redundantes, superficiais e próximas ao lugar-comum.

Sobre esse aspecto Tomaz Tadeu da Silva (1999, p. 139) aponta que:

Tanto a educação quanto a cultura em geral estão envolvidas em processos de transformação da identidade e da subjetividade. (...) através dessa perspectiva, ao mesmo tempo que a cultura em geral é vista como uma pedagogia, a pedagogia é vista como uma forma cultural: o cultural torna-se pedagógico e a pedagogia torna-se cultural.

Sendo assim, ao observarmos os processos educativos da contemporaneidade - os quais se solidificaram e são sustentados por relações sociais no exercício das pedagogias culturais em suas diferentes ações, nuances e estratégias - identificamos que os mesmos criaram rachaduras à hierárquica estrutura escolar e familiar da Modernidade. Hoje em dia, a noção de educação, ao mesmo tempo em que é ampliada, dilui-se pelo espectro social como os "líquidos" (BAUMAN, 2001). Notoriamente, diferentes esferas sociais e culturais produzem educação e as práticas pedagógicas desenvolvidas por essas esferas mostram-se revestidas por uma espécie de novo "código de civilidade", fixando a necessidade de uma formação/educação que se dá na relação dos sujeitos com os inúmeros signos postos no contemporâneo (BUJES, 2002).

Dito isto, vale ressaltar que as pesquisas do campo dos Estudos Culturais, assim como as dos Estudos de Gênero, atravessadas por esse conceito de pedagogia cultural possibilitam-nos olhar para além da escola e entender que não é somente em seu interior que se produz educação. No intuito de dar andamento a essa narrativa passaremos a apresentar algumas das especificidades de caracterizam os Estudos de Gênero, ressaltando sua íntima relação com os conceitos de cultura e pedagogia cultural.

\section{Estudos de Gênero: arranjos, tramas e composições investigativas}

Inúmeras pesquisas têm sido desenvolvidas imersas nesse campo de investigação estudando a produção das identidades de gênero, tanto na escola como fora dela. Suas pesquisas têm contribuído, significativamente, para problematizar as diferenças conferidas a homens e mulheres, a meninos e meninas, produzidas na esteira da cultura. Certamente, uma de suas contribuições para o campo da educação seja justamente a de relativizar a centralidade que alguns estudos sobre tais diferenças, principalmente direcionadas de áreas como a biologia e a 
medicina, as quais alegam que nossos corpos e nossas identidades são naturalmente dados, têm no bojo desses estudos.

Sem ter o intuito de marcar o seu começo, ou ainda, o seu início, mas, sim, de apontar o modo como essa perspectiva de estudos se projeta no debate educacional, construindo trajetórias diferenciadas que modifica, significativamente, a paisagem epistemológica sobre o conceito de gênero, faremos um sucinto resgate das duas ondas do movimento feminista no século XX, berço dos Estudos de Gênero.

Conforme aponta Dagmar Meyer (2007), algumas historiadoras feministas, em geral, apresentam como referência do movimento feminista dois significativos momentos históricos. $O$ primeiro deles, que remete a uma primeira onda do feminismo, aglutina-se do movimento sufragista que buscou direitos iguais entre homens e mulheres. A luta pelo direito ao voto caracteriza um destes ganhos dados às mulheres. Em termos de Brasil, vale salientar, que tal benefício só fora garantido com a Constituição de 1934, mais de quarenta anos após a Proclamação da República. Justamente com tal ganho, outras lutas travadas pelas mulheres passaram a ser desenvolvidas. Entre elas sobressaem-se o exercício da docência, as condições de trabalho, a realização do ensino superior, entre outras.

Nesse período já convergiam diferentes vertentes do feminismo, as quais proliferavam no corpus social estudos, manifestos e reivindicações das mulheres. Correntes consideradas mais burguesas e liberais, lutando pelo direito ao voto; outras de caráter mais político, aliadas aos movimentos sociais, na busca pelo direito à educação; e ainda àquelas de vertente anarquista, na luta pelo direito das mulheres de decidir sobre os destinos dados aos seus corpos e à vivência das suas sexualidades já se encontravam em vigor na pauta dos movimentos feministas, caracterizando-os.

Outro momento histórico que marca o que é concebido como a segunda onda do feminismo encontra abrigo nos anos 60 e 70 do século passado. No Brasil, essa vertente do feminismo eclode com movimentos políticos e sociais de oposição à ditadura militar. Adiante, já nos anos 80 , essa vertente polariza-se com os movimentos de redemocratização da sociedade brasileira. Na esteira das discussões e lutas dessa onda feminista visibilizaram-se o maciço investimento na produção intelectual sobre gênero, possibilitando o desenvolvimento de pesquisas e estudos que não apenas buscavam denunciar as diferenciações entre homens e mulheres construídas social, histórica, culturalmente, mas, fundamentalmente, na busca por problematizar essa subordinação histórica que minorava as mulheres em relação aos homens.

Segundo Meyer (2007, p. 13):

Essa trajetória rica e multifacetada do feminismo também foi, e é, permeada por confrontos e resistências tanto com aqueles e aquelas que continuavam utilizando e reforçando justificativas biológicas ou teológicas para as diferenças e desigualdades entre as mulheres e os homens, quanto com aqueles que, desde perspectivas marxistas, defendiam a centralidade da categoria de classe social para a compreensão das diferenças e desigualdades sociais.

Contemporaneamente, as estudiosas feministas se desafiam frente ao histórico binômio de ordem biológica homem $x$ mulher, na busca por demonstrar que não são as características fisiológicas e anatômicas, nem ao menos distinções socioeconômicas, vistas isoladamente, que tem o poder de definir diferenças e inferioridades às mulheres.

Joan Scott (1995) considera o conceito de gênero como produto de um profícuo trabalho de mulheres inseridas no movimento feminista, no intuito de cunhar o entendimento de que ele não é algo ligado ao determinismo biológico. Essa possibilidade de ampliar a 
compreensão sobre o significado que se atribui ao conceito de gênero é resultado das movimentações sociais e políticas dos anos 1960 e 1970, em especial. Por esse período intensifica-se a noção de que não se nasce homem ou mulher. Compreende-se que são ensinados atributos e legados, por meio de discursos e representações sociais e culturais, que promovem a produção de diferentes posições de sujeito, imbricados na constituição de suas identidades.

No bojo desses estudos e movimentos feministas foram debatidas questões relevantes e até mesmo, centrais, no intuito de desnaturalizar distinções essencializadas sobre os termos masculino e feminino, uma vez que os mesmos são compreendidos como termos recíprocos e não como definições separadas uma da outra. Justamente por acolher essa noção é que se torna cada vez mais coerente e importante falar em relações de gênero. Ao utilizar essa expressão mostramos a relevância que a mesma carrega: são os modos distintos de se constituírem homens e mulheres, na esteira da cultura, atravessados por discursos e representações, que ganham destaque no cenário atual de tais investigações.

A crítica pós-estruturalista, complexificada pelas suas estudiosas feministas, tem buscado problematizar noções de corpo e sexualidade agregadas ao conceito de gênero. Tudo isso, na tentativa de romper com uma visão superficial de que o sexo anatômico confere a homens e mulheres, de modo natural, dado e inato, características que os diferenciam e assim constituem suas desigualdades e, tão logo, inferioridades femininas. Na linha de pensamento dessas estudiosas, as diferenças e desigualdades constituídas sobre homens e mulheres não são da ordem da biologia: elas são social, cultural e historicamente construídas e situadas, e não determinadas pelo viés da anatomia de seus corpos.

Com essa proliferação de estudos e a polissemia de significados e sentidos múltiplos acerca do conceito de gênero dentro do feminismo em diversas localidades mundiais, foi possível assentar algumas considerações fundamentais: uma delas é a de que ao longo de nossas vidas, imersos/as nas diferentes instâncias nas quais estamos inseridos/as vamos nos constituindo como homens e mulheres, processo esse que nunca se encontra finalizado, esgotado. Outra assertiva desses estudos propõe a compreensão de que nascemos e vivemos em espaços, tempos e ocasiões específicos e diversificados, assumindo representações que definem múltiplas formas de se viver e experimentar as feminilidades e as masculinidades.

Exatamente porque o conceito de gênero enfatiza essa pluralidade e conflitualidade dos processos pelos quais a cultura constrói e distingue corpos e sujeitos femininos e masculinos, torna-se necessário admitir que isso se expressa pela articulação de gênero com outras "marcas" sociais, tais como classe, raça/etnia, sexualidade, geração, religião, nacionalidade. É necessário admitir também que cada uma dessas articulações produz modificações importantes nas formas pelas quais feminilidades ou as masculinidades são, ou podem ser, vividas e experienciadas por grupos diversos, dentro dos mesmos grupos ou, ainda, pelos mesmos indivíduos, em diferentes momentos de sua vida (MEYER, 2007, p. 17). [grifos da autora]

Atualmente, os Estudos de Gênero têm produzido e contribuído com as pesquisas educacionais tencionando e problematizando essa noção, uma vez que nos desestabilizam e nos fazem desconfiar de certezas postas em circulação e vigor em torno do corpo e das identidades de gênero no espectro social. Nessa perspectiva de análise, os corpos femininos e masculinos se afastam de vertentes que os analisam como algo dado e inato, resultado de uma ordem biológica "existente na consciência no momento do nascimento" (MEYER, 2007). Do mesmo modo esses estudos distanciam-se de correntes que o veem estritamente como uma entidade universal, extrapolando a noção de que os mesmos sejam naturais e essencializados, construção cultural e 
histórica de caráter biologicista que muito vigorou (e por vezes ainda vigora) em nossa sociedade (BUTLER, 2007; SABAT, 2004, 2007; WEEKS, 2007).

Nessa perspectiva teórica, assim como afirma Guacira Lopes Louro (2000; 2007; 2007a; 2007b), o próprio conceito de gênero é aquele que privilegia a multiplicidade de vozes, de identidades e, portanto, de diferenças entre homens e mulheres, uma vez que não abrange, apenas, a noção/oposição existente entre os sexos. É compreendido, pois, como uma construção social que se encontra em constante transformação e parte do pressuposto que homens e mulheres estão inseridos em diferentes culturas, vivem essas diferenças e, portanto, legitimam e estabelecem, em suas constituições identitárias, relações de saber, poder e significação.

Confirmando esse pressuposto, nas palavras de Silva (1999, p. 91):

"Gênero" opõe-se, pois, ao "sexo": enquanto este último termo fica reservado aos aspectos estritamente biológicos da identidade sexual, o termo "gênero" refere-se aos aspectos socialmente construídos do processo de identificação sexual. Essa separação é hoje questionada por algumas perspectivas teóricas, que argumentam que não existe identidade sexual que não seja já, de alguma forma, discursiva e socialmente construída, mas a distinção conserva sua utilidade. [grifos do autor]

Portanto, para os Estudos de Gênero - que compreendem o caráter efêmero e transitório do corpo - a ideia de base biológica e binária (homem $\mathrm{x}$ mulher) vai dando abertura e espaço nas teorizações para o entendimento de que o corpo (e a sexualidade) são constructos sociais, culturais, políticos e historicamente engajados, constituídos e situados, marcados por signos e códigos do tempo presente.

Ainda assim é importante salientar que embora as identidades de gênero e as identidades sexuais mantenham entre si uma relação, que a mesma não é sustentada por um caráter de dependência. O que isso significa? Que as identidades sexuais (o que é da ordem dos desejos, dos prazeres e da vivência da sexualidade) não são fixas, terminais e dependentes por conta do sexo biológico dotado dos sujeitos. As identidades de gênero (o que é da ordem das feminilidades e das masculinidades) são construções sociais e culturais, e não estão 'presas' ao sexo biológico de homens e mulheres.

Scott (1995) e Louro (2007), entre outras estudiosas do conceito de gênero o tem compreendido como uma "categoria relacional". Relacional no sentido de perceberem existir uma relação estabelecida entre homens e mulheres. A dizer isso convergem com a noção de que a construção do feminino se dá levando-se em conta os aspectos estritamente vinculados ao masculino. Tão logo se aceita essa premissa, percebe-se o movimento oposto - a construção do masculino levando-se em conta o feminino - , instaurado e em vigor.

(...) 'gênero', além de um substituto para o termo mulheres, é também utilizado para sugerir que qualquer informação sobre as mulheres é necessariamente informação sobre os homens, que implica o estudo do outro. Essa utilização enfatiza o fato de que o mundo das mulheres faz parte do mundo dos homens (...) (SCOTT, 1995, p. 75). [grifos da autora]

Nessa relação entre os gêneros masculino e feminino, articulações com outras categorias, sejam elas geração, etnia, raça, cor, classe social, sexualidade, entre outras, têm sido desenvolvidas e propostas em diversos estudos. A preocupação em investigar concepções essencializadas, aquelas dadas como universais no que se refere ser o 'próprio' do feminino e do masculino possibilitam a proliferação de muitos estudos que visam contribuir com a teorização social e cultural acerca do conceito e das relações de gênero. 
Nesse sentido, como já fora mencionado, percebendo a amplitude da temática, não ficam grifados no conceito de gênero ideias superficiais acerca da diferenciação de 'papeis' sociais e as 'funções' distintivas das figuras femininas e masculinas. Resumidamente, podemos dizer que à categoria gênero ficam relacionados os aspectos da ordem da produção das feminilidades e das masculinidades.

\title{
Cultura e Gênero: relações e implicações em pesquisas educacionais na Infância
}

\begin{abstract}
Portanto, a pesquisa nasce sempre de uma preocupação com alguma questão, ela provém, quase sempre, de uma insatisfação com respostas que já temos, com explicações das quais passamos a duvidar, com desconfortos mais ou menos profundos em relação a crenças que, em algum momento, julgamos inabaláveis. Ela se constitui na inquietação (BUJES, 2002a, p. 14). [grifos da autora]
\end{abstract}

Após termos discorrido sobre aspectos centrais dos Estudos Culturais e dos Estudos de Gênero, ambos alicerçados na perspectiva teórica pós-estruturalista, bem como após ter apresentado alguns de seus conceitos utilizados em nossas pesquisas, temos o interesse em conduzir este ensaio para sua conclusão, demarcando as contribuições que apontamos de tais campos em nossas investigações, em especial no que tange à infância.

A noção de infância percorrida nas pesquisas dos Estudos Culturais e dos Estudos de Gênero não é tomada como homogênea, fixa, naturalmente dada, nem ocupa a categoria de universal, uma vez que se considera que distintos modos de produzi-la ocorrem em diferentes locais geográficos. Do mesmo modo, a infância não é entendida como um período de inocência e de pureza, que precisa ser assim cultivado.

Embora se compreenda por infância o período de vida que vem sendo historicamente construído e estabelecido para o exercício de determinadas práticas sociais e culturais destinadas às crianças, em especial no Ocidente, na perspectiva pós-estruturalista o termo infâncias propõe-se mais profícuo, justamente por ampliar a noção de tempo histórico e por referir-se ao modo como essa etapa da vida constantemente inventada e produzida é experimentada, explorada e vivenciada pelas diferentes crianças imersas em suas distintas culturas, sociedades, raças e etnias. O termo infâncias leva em consideração as inúmeras intervenções culturais e sociais que às crianças são legitimadas. Nessa perspectiva as infâncias são percebidas como algo que nos escapa, que desconcerta nossas certezas, nossos saberes e coloca em voga o que historicamente tem sido posto como verdade e construído para elas. As infâncias mostram-se revestidas numa rede de complexas relações, entremeadas com as produções culturais, sociais e históricas, não resultando de um processo evolutivo, como algumas perspectivas tentam-na fixar e enquadrar.

Diante desse entendimento traçado e ao acolher a noção de que as infâncias são atravessadas por pedagogias que a educam, a constroem, a inventam e assim a circunscrevem no tempo presente, aceitamos seu caráter volúvel de provisoriedade, uma vez que compreendemos que as pedagogias que atuam no hoje dessas infâncias, provavelmente, não serão as mesmas do porvir.

Sendo assim, ao estudar aspectos relacionados à infância a partir da perspectiva pósestruturalista não intentamos, conforme salienta Bujes (2002a, p. 16), tratar de

apontar como se constituiu na Modernidade um conceito de infância, de como esta foi "descoberta" como uma preocupação social, ou de como um discurso sobre a infância passou a ser manifestado de forma ampla em quase todas as camadas da sociedade". [grifos da autora] 
Nessa direção, a perspectiva teórica adotada instiga e ao mesmo tempo desafia justamente porque se afasta de análises essencialistas e totalizantes; não concebe a infância de um modo idealizado, não toma a criança como um dado biológico que sofre influências do seu meio, nem compreende as crianças como seres frágeis e inocentes.

Enfim, vale grifar que os conceitos e os estudos que aqui foram analiticamente delineados são o que são por serem construídos, constantemente, no movimento da história, da sociedade e da cultura. Por isso mesmo é que tem grande relevância para a pesquisa educacional. No mais, podemos ainda afirmar que os diversos significados hoje atribuídos às infâncias são resultados da produção de processos históricos. Com efeito, poder situá-los numa rede de práticas sociais e culturais de significação, tomando como fundamentos os Estudos Culturais e os Estudos de Gênero, tem nos possibilitado análises que se afastam de versões contemplativas, levando-nos a seguinte proposição: o que torna, em nossas práticas educacionais, algo pensável?

\section{REFERÊNCIAS BIBLIOGRÁFICAS}

1. BARBERO, J. M. Dos meios às mediações. Comunicação, cultura e hegemonia. Rio de Janeiro: Editora UFRJ, 2003.

2. BAUMAN, Z. Modernidade Líquida. Rio de Janeiro: Jorge Zahar, 2001.

3. Vida para Consumo: a transformação das pessoas em mercadoria. Rio de Janeiro: Jorge Zahar, 2008.

4. BUJES, M. I. E. Infância e maquinarias. Rio de Janeiro: DP\&A, 2002.

5. Descaminhos. In.: COSTA, M. V. (org.). Caminhos Investigativos II: outros modos de pensar e fazer a pesquisa em educação. Rio De Janeiro: DP\&A, 2002.

6. BUTLER, J. Corpos que pensam: sobre os limites discursivos do "sexo". In.: LOURO, Guacira Lopes (org.). O Corpo educado: pedagogias da sexualidade. Belo Horizonte: Autêntica, 2007.

7. CANCLINI, N. G. Consumidores e Cidadãos. Rio de Janeiro: Editora UFRJ, 2001.

8. COSTA, M. V.; SILVEIRA, R. H.; SOMMER, L. H. Estudos Culturais, educação e pedagogia. Revista Brasileira de Educação, n. 23, maio/jun./jul./ago. 2003.

9. FISCHER, R. M. B. Verdades em suspenso: Foucault e os perigos a enfrentar. In.: COSTA, Marisa Vorraber (org.). Caminhos Investigativos II: outros modos de pensar e fazer a pesquisa em educação. Rio de Janeiro: DP\&A, 2002.

10. GIROUX, H. Praticando Estudos Culturais nas Faculdades de Educação. In: SILVA, Tomaz Tadeu da (org.). Alienígenas na sala de aula: uma introdução aos Estudos Culturais em Educação. 3 ed. Petrópolis/RJ: Vozes, 1995.

11. GIROUX, H.; McLAREN, P. Por uma pedagogia crítica da representação. In: SILVA, T. T.; MOREIRA, A. F. (orgs.). Territórios Contestados: o currículo e os novos mapas políticos e culturais. 2.ed. Petrópolis: Vozes, 1998.

12. LOURO, G. L. Corpo, escola e identidade. Porto Alegre: FACED/UFRGS, Educação e Realidade, v. 25, n. 2, 2000.

13. Pedagogias da Sexualidade. In.: LOURO, Guacira Lopes (org.) O Corpo Educado: pedagogias da Sexualidade. Belo Horizonte: Autêntica, 2007. 
14. . Currículo, gênero e sexualidade. O "normal", o "diferente" e o "excêntrico". In.: LOURO, G. L.; FELIPE, J.; GOELLNER, S. V. Corpo, gênero e sexualidade: um debate contemporâneo na educação. Petrópolis: Vozes, 2007a.

15. Gênero, sexualidade e educação: uma perspectiva pós-estruturalista. Petrópolis: RJ, Vozes, 2007b.

16. MEYER, D. E. E. Gênero e educação: teoria e política. In.: LOURO, G. L.; FELIPE, J.; GOELLNER, S. V. Corpo, gênero e sexualidade: um debate contemporâneo na educação. Petrópolis: Vozes, 2007.

17. SABAT, R.. Só as bem quietinhas vão casar. In.: MEYER, D.; SOARES, R. F. R. (orgs.). Corpo, gênero e sexualidade. Porto Alegre: Mediação, 2004.

18.

Gênero e sexualidade para consumo. In.: LOURO, G. L.; FELIPE, J.; GOELLNER, S. V. Corpo, gênero e sexualidade: um debate contemporâneo na educação. Petrópolis: Vozes, 2007.

19. SCOTT, J.. Gênero: uma categoria útil de análise histórica. Educação e Realidade. Porto Alegre: FACED/UFRGS, v. 20, n. 2, jul./dez. 1995.

20. SILVA, T. T. Documentos de Identidade: uma introdução às teorias do currículo. Belo Horizonte: Autêntica, 1999.

21.

- Currículo como Fetiche: a poética e a política do texto curricular. Belo Horizonte: Autêntica, 2001.

22. WEEKS. J. O Corpo e a Sexualidade. In.: LOURO, G. L. (org.). O corpo educado: pedagogias da Sexualidade. Belo Horizonte: Autêntica, 2007. 